\title{
Prevention of Breast Cancer Could Be a Consequence of Pregnancy: A Review
} Jose Russo*

The Irma H. Russo MD Breast Cancer Research Laboratory, Fox Chase Cancer Center, Temple University Health System, Philadelphia, USA

*Corresponding author: Jose Russo MD, Fox Chase Cancer Center, 333 Cottman Avenue, Philadelphia, PA 19111, USA, Tel: 215-728-4782; Fax: 215-728-2180; Email: jose.russo@fccc.edu

Received date: May 14, 2014, Accepted date: Jun 12, 2014, Published date: Jun 16, 2014

Copyright: (c) 2014 Russo J, et al. This is an open-access article distributed under the terms of the Creative Commons Attribution License, which permits unrestricted use, distribution, and reproduction in any medium, provided the original author and source are credited.

\begin{abstract}
The genomic profile of parous women has shown that genes which are activated only within the first five years after pregnancy, may contribute to the increased risk of breast cancer in certain women. At the same time, pregnancy's protective effect is induced by a long-lasting genomic signature. This signature reveals that the differentiation process is centered around chromatin remodeling and represents a safeguard mechanism at genomic and post-transcriptional levels that maintains the fidelity of the transcription process, which could be the ultimate step mediating the protection of the breast conferred by full term pregnancy.
\end{abstract}

Keywords: Pregnancy; Breast cancer; Parous women

\section{Introduction}

Breast cancer is a heterogeneous and complex disease resulting from the uncontrolled growth of cells that are unique and specific to the breast. The disease affects women of all races and nationalities [1-3]. The worldwide incidence of breast cancer has increased $30-40 \%$ since the 1970 s, reaching a more than $1,400,000$ new cases and a mortality of more than half a million by 2014 [2-6].

Epidemiological, clinical and pathological studies have uncovered novel aspects regarding the complexity of this disease [7-9]. We know that age at diagnosis and ethnicity are associated with a specific tumor type and tumor behavior, which in turn are influenced by a woman's age at the first pregnancy [10,11]. This indicates that the global incidence of breast cancer changes over time in relation to geography, race and lifestyle changes, suggesting that breast cancer risk is influenced by a multiplicity of still undefined factors. Reproductive history is a common denominator for breast cancer risk $[7,8,11]$. Increased breast cancer incidence and mortality were associated with nulliparity as early as the 1700 s, as reported by Bernardino Ramazzini, who attributed the phenomenon to the childlessness of nuns in Italian convents [12]. MacMahon et al. [8] reported that pregnancy exerted a protective effect in women who bore children from their early teen years to their mid-twenties, relative to a risk of 100 for nulliparous women. Numerous studies have confirmed these results and have additionally reported that multiple pregnancies significantly decrease the risk of developing breast cancer after age 50 [8], whereas full-term pregnancy later in life increases a woman's breast cancer risk, reaching the same levels observed in nulliparous women when it occurs between 30 to 34 years of age, increasing even further after 35 years $[7,8]$. An understanding of the mechanisms that determine whether a pregnancy would prevent breast cancer or increase its risk requires taking into consideration not only the age at the first pregnancy but also the age at the time of breast cancer diagnosis, which in turn influences the stage and pathological characteristics of the tumors developed [13-15].

\section{Pregnancy}

Pregnancy itself is a complex process that only succeeds when a woman's ovaries are fully functional and secrete estrogen and progesterone, hormones that are essential for the maintenance of pregnancy. The ovaries work under the control of the hypothalamicpituitary-gonadal (HPG) axis [16,17], which synchronizes the ovarian secretions with those of pituitary and placental hormones for stimulating breast development in preparation for milk production $[17,18]$. Primiparous women younger than 25 years of age who have elevated serum levels of hCG during their first trimester have 33\% decreased risk of a breast cancer diagnosis after age 50, whereas estrogen concentrations have been positively associated with risk of breast cancer before age 40, supporting the role of this or other pregnancy hormones in the development of breast cancer [19-23].

\section{When does a full term pregnancy reduce breast cancer risk?}

In experiments performed in rats, pregnancy, the gold standard for the induction of mammary gland differentiation, needs to be completed to prevent mammary cancer. In rats it has been shown that when their first pregnancy was interrupted 12 days after conception and they received DMBA 21 days later [24] the tumor incidence and number of tumors per animal in pregnancy-interrupted rats and agematched virgin rats were similar, whereas rats that completed their pregnancy had a significantly reduced tumorigenic response. Completion of the first pregnancy results in full differentiation of the mammary gland that culminates in the secretion of milk, which persists during the length of the lactational period [17,22]. At postweaning the lobular structures regress and the remaining cells exhibit a marked reduction in proliferative rate, lengthening in the G1 phase of the cell cycle, greater capabilities to repair DNA damaged by the carcinogen and lower affinity for binding DMBA to DNA [22]. These structural, functional and molecular changes persist in the mammary gland, resulting in a significant reduction of mammary cancer incidence that is evident in various strains of rats and mice [25], in spite of histopathological differences in tumor type between these species. Blakely at al. [26] have confirmed that in four genetically distinct inbred strains of rats (Lewis, Wistar-Furth, Fischer 344, and Copenhagen) and in mice pregnancy and lactation induce similar 
structural and genomic changes in mammary glands studied by microarray analysis. Gene analysis identified a genomic signature that sufficed for distinguishing nulliparous from parous animals and explain the almost total refractoriness of the parous rat mammary gland to develop carcinomas after carcinogen administration [26,27]. These observations indicate that when the development of the mammary gland has been completed by an early pregnancy, steroid hormone- or hCG treatment of virgin animals the period of maximal susceptibility to cancer (PMSC) or Stem Cells (EUN) has completed a first cycle of differentiation under specific hormonal influences, becoming a Stem Cell of HTN [28], which is resistant to transformation by a carcinogen. Although more differentiated, the HTN cells have retained the capacity to regenerate the complete lobular system required by subsequent pregnancies. This concept has been further demonstrated in transgenic WAP-driven Cre and Rosa 26-fl-stop-fl-LacZ mice in which parity-induced mammary epithelial cells (PI-MEC) originated from differentiated cells during pregnancy, survived post lactational involution and increased their percentage with successive pregnancies [29]. PI-MEC, like the HTN cells in the parous rat mammary gland, show capacity for self-renewal and contribute to mammary outgrowth in transplantation studies. PI-MEC can function as alveolar progenitors in subsequent pregnancies, and it is thought that they would be related to differences in response to hormonal stimulation and carcinogenic agents observed between nulliparous and parous females [30-32].

The relevance of the findings that the first full term pregnancy occurring during the high risk susceptibility window (HRSW) (Figure 1) but before exposure to a carcinogen prevents cancer initiation is equivalent to the well demonstrated protective effect of an early first full term pregnancy (FTP) in women. A first FTP initiated approximately two weeks after carcinogen exposure, on the other hand, results in a high incidence of mammary cancer, a phenomenon that could explain the increased cancer risk observed in women first parous after age 30, supporting the assumption that during that lengthened HRSW (Figure 1) the breast has been exposed to carcinogenic stimuli before pregnancy. These data emphasize the importance of discriminating whether the first pregnancy would produce protection by inducing complete differentiation of the breast activating the same mechanisms that hormonal treatments do, or would increase breast cancer risk as a consequence of genotoxic or epigenetic exposures during the HRSW (Figure 1).

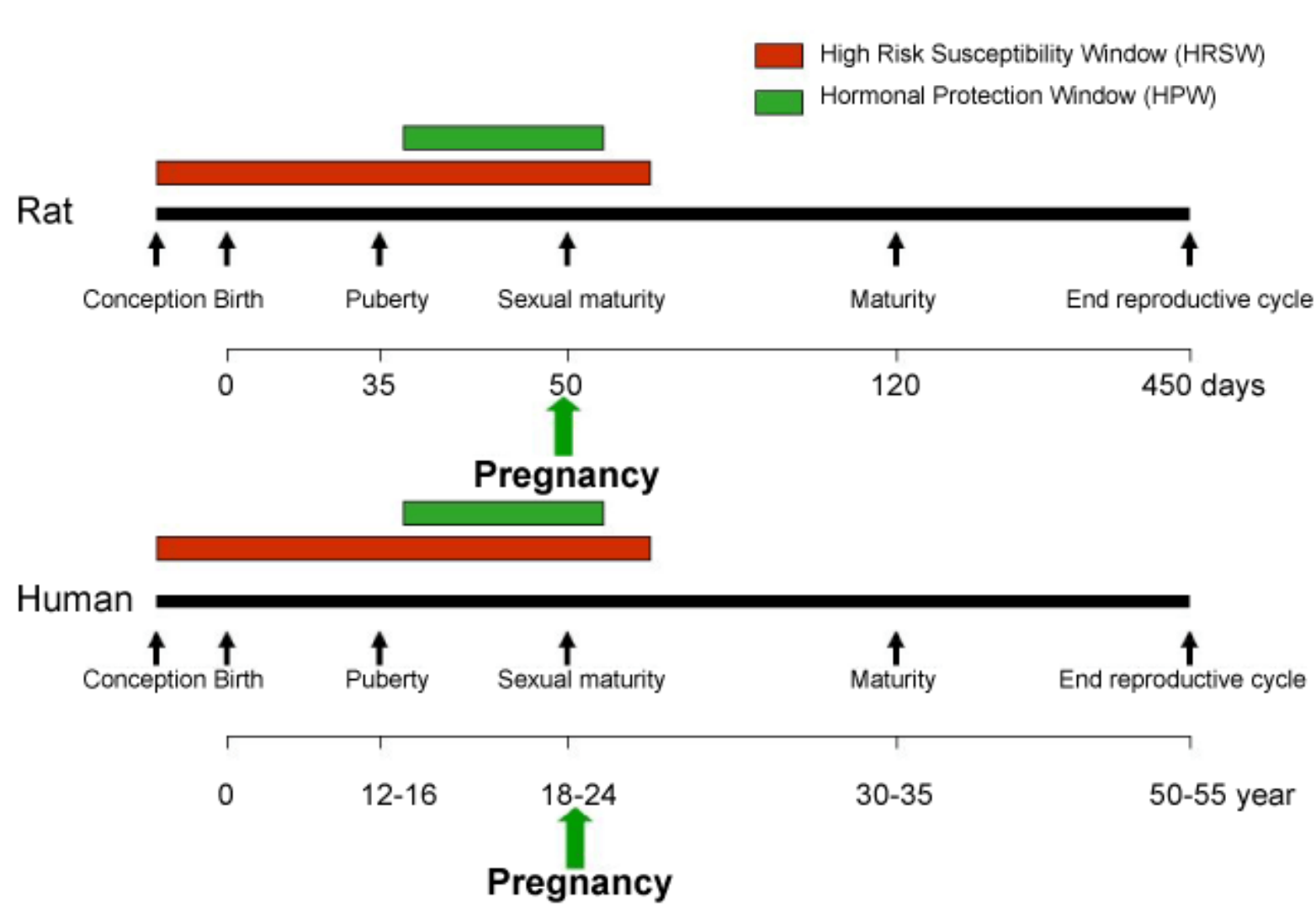

Figure 1: Diagrammatic representation of mammary gland development from conception to the end of reproductive life. In both rats (upper line) and humans (lower line) the period of life that begins in uterus and persists until sexual maturity, represents a window of greater susceptibility of the mammary gland to be damaged by exogenous carcinogenic stimuli or exposure to endocrine disruptors. The differentiation of the mammary gland induced by pregnancy or the appropriate hormonal treatments needs to occur during the post-pubertal period and before the mammary epithelium has suffered any damage, representing a hormone-driven window of protection that overrides the high risk window. HRSW, high risk susceptibility window, red bar; HPW, hormonal protection window, green bar. (Adapted from: Russo and Russo. Pregnancy-induced changes in breast cancer risk. A review. J Mammary Gland Biol Neoplasia 16:221-233, 2011). 


\section{The human breast in pregnancy and disease}

The development of the breast is a continuous process initiated by the fourth week of intrauterine life that progresses under the influence of maternal, placental and environmental factors until birth and by diet and by environmental exposures after weaning. During these periods the maturation of the hypothalamic gonadal (HPG) axis $[16,17,33]$ and endogenous hormone secretions play essential roles on the development of the breast at puberty, which is driven by the initiation of ovulation and the establishment of regular menstrual cycles [34]. The architecture of the breast of normally cycling women has been widely described as composed of three main lobular structures that are classified on the basis of their degree of development into lobules type 1 (Lob 1), lobules type 2 (Lob 2) and lobules type 3 (Lob 3) $[22,35,36]$. The breasts of women who have never conceived a child remain composed of Lob 1, with moderate formation of Lob 2 with successive menstrual cycles; Lob 3 become present only occasionally during the early reproductive years. After menopause the breast further regresses, resulting in an increase in the number of Lob 1 in response to the decline in Lob 2 and Lob 3 with aging. It has been shown that the breast parenchyma of postmenopausal nulliparous women contains predominantly euchromatin nucleus (EUN) cells [28], which do not achieve the most differentiated stage of heterochromatin nucleus (HTN) cells due to the absence of pregnancy, therefore retaining their susceptibility to be transformed. Therefore, a carcinogenic insult or an inappropriate hormonal stimulus, such as hormone replacement therapy [37], would transform the EUN cells into a cancer stem cell.

\section{Breast development under the endocrinological influence of pregnancy}

The development of the breast from birth to puberty follows a general pattern common for all normally cycling women, with the formation of Lob 1, Lob 2 and Lob $3[35,36]$. The progression of lobular development under the cyclic influence of ovarian hormones is rapidly accelerated during the first pregnancy, which to be successful requires the timely fertilization of an oocyte followed by its uterine implantation. The embryo drives a process that establishes a collaboration of the newly formed placenta with the maternal environment [38]. The placenta alone elaborates a myriad of proteins, glycoproteins, steroid hormones, growth factors, tumor suppressor factors and cytokines that control the local environment of the fetus and regulate the metabolic activities of both the mother and the fetus [39]. In addition to estrogen and progesterone, newly secreted hormones, such as human growth hormone (hGH), hCG, human placental lactogen (hPL), and inhibin stimulate breast development and differentiation [40,41]. Elevated serum levels of Metastin (KISS1) have been detected during pregnancy [42], but the role of this hormone in breast development has not been identified as of yet. LH, progesterone and hCG are the main hormones driving the initial phase of growth, followed by the secretion of the pituitary hormone prolactin (PRL) that stimulates milk secretion and contributes to the development of the fully differentiated Lob 4 during the last trimester of pregnancy and lactation. After weaning, Lob 4 regresses to Lob 3, which persists in the breast as long as women continue cycling. At perimenopause the number of Lob 3 progressively decreases due to their involution to Lob 2 and Lob 1 [22].

\section{Cellular and molecular basis of the protective effect of early pregnancy in the postmenopausal women}

The morphological, physiological and genomic changes resulting from pregnancy and hormonally-induced differentiation of the breast and their influence on breast cancer risk have been addressed above and in the literature [43-48]. The observations that during the postmenopausal years the breasts of both parous and nulliparous women contain predominately Lob 1 , and the fact that nulliparous women are at higher risk of developing breast cancer than parous women, indicate that Lob 1 in these two groups of women either differ biologically, or exhibit different susceptibility to carcinogenesis [46]. Novel markers showing changes in cell types and increases in chromatin condensation define the concept of differentiation in the adult breast and further clarify this concept [28]. These findings confirm the universality of the histone 3 methylation in lysines 9 and 27 during differentiation, since a similar phenomenon has been described to occur during embryonic stem cell (ESC) differentiation [49]. The observed chromatin changes in parous epithelial cells are complemented by the expression of genes related to increasing cell adhesion, such as NRXN1, DSC3. COL27A1, PNN, COL4A6, LAMC2, COL7A1, COL16A1, and LAMA3, and differentiation, that include MGP KRT5 GATA3 and LAMA3 [28,48].

In contrast to the findings of other authors [50] looking at down regulation of the expression of ER- $\alpha$ following recent ( 0 to 2 y since last pregnancy) and distant (5 to $10 \mathrm{y}$ since pregnancy) pregnancies in premenopausal women, the genomic and IHC study in postmenopausal breast did not reveal differences in the level of expression of ER- $\alpha$ in the epithelial cells of ducts and Lob 1 between parous and nulliparous postmenopausal women. Nevertheless, numerous genes that are regulated downstream by ER- $\alpha$ were found to be up regulated in the parous breast, supporting parity mediated protective effect evident in younger parous women [50] but lasting until menopause. Among the ER- $\alpha$ downstream regulated genes was GATA3, which encodes a protein that belongs to the GATA family of transcription factors that regulates $\mathrm{T}$ lymphocyte differentiation and maturation. GATA3 is crucial to mammary gland morphogenesis and differentiation of progenitor cells and a putative tumor suppressor [51]. Induction of GATA 3 expression in GATA3-negative undifferentiated carcinoma cells is sufficient to induce tumor differentiation and inhibition of tumor dissemination [52]. Therefore, the observation that genes involved in the estrogen receptor regulated pathways are upregulated in the parous breast in spite of the lack of transcriptomic differences in this receptor's levels between parous and nulliparous postmenopausal breast tissues suggests that they could be under permanent transcriptional modification as a manifestation of a higher degree of cell differentiation.

Studies of breast development under the influence of parity in women and in animal models are in agreement on the pregnancyinduced differentiation of the breast, a process that ultimately becomes manifested as a specific genomic signature in the mammary gland [43-45,47,50,53,54]. Although variations in gene expression among different studies and species are expected, an increase in immune activity, including overexpression of lipopolysaccharide binding protein (LBP/Lbp) has been reported in the post-pregnancy breast of premenopausal women [50] and in the mammary gland of four different strains of rats [53]. Interestingly, this response was observed in both recently pregnant in distant pregnant groups but not in the postmenopausal group. These discrepancies might indicate that the up 
regulation of inflammation/immune response-related genes persists during post-partum involution, but wanes after menopause sets in.

Importantly, there has been a reported shift in the cell population of the postmenopausal breast as a manifestation of the reprogramming of the organ after pregnancy [28]. These observations are in agreement with what is observed in the rat mammary gland, which also contains two types of luminal epithelial cells, designated dark (DC) and intermediate (IC) cells, in addition to the myoepithelial cells [55]. The DC and IC are equivalent to the HTN and EUN cells described in the parous breast [28]. DCs increase after pregnancy and lactational involution; whereas the ICs significantly outnumber the DCs in ductal hyperplasias and ductal carcinomas [55,56]. The analysis of nuclear ultrastructural and morphometric parameters of rodent ICs have allowed us to differentiate the mammary progenitor stem cell from the cancer stem cells $[46,55,56]$. Nuclear morphometric analysis of breast and ovarian carcinomas has confirmed the predictive value of nuclear grade on the progression of premalignant lesions to invasiveness [57-59]. The findings of a significant decrease in the number of EUN with a subsequent increase in the number of HTN cells expressing specific biomarkers identified at the chromatin and transcriptional levels support the value of morphometric analysis as an adjuvant to molecular studies. The data clearly indicate [28] that there are morphological indications of chromatin remodeling in the parous breast, such as an increase in the number of epithelial cells with condensed chromatin and increased reactivity with anti-H3K9me2 and H3K27me3 antibodies. Histone methylation is a major determinant for the formation of active and inactive regions of the genome and is crucial for the proper programming of the genome during development [60]. In the parous breast there is up regulation of transcription factors and chromatin remodeling genes such as CHD2 or chromodomain helicase DNA binding protein 2 and the CBX3 or Chromobox homolog 3 , whose products are required for controlling recruitment of protein/protein or DNA/protein interactions. CBX3 is involved in transcriptional silencing in heterochromatin-like complexes, and recognizes and binds $\mathrm{H} 3$ tails methylated at lysine 9, leading to epigenetic repression. Two other important genes related to the polycomb group (PcG) protein that are up regulated in the parous breast are the L3MBTL gene or 1(3)mbt-like and the histone-lysine Nmethyltransferase or EZH2. Members of the PcG form multimeric protein complexes that maintain the transcriptional repressive state of genes over successive cell generations. EZH2 is an enzyme that acts mainly as a gene silencer, performing this role by the addition of three methyl groups to lysine 27 of histone 3, a modification that leads to chromatin condensation go $[49,61,62]$.

Recent studies indicate that RNA molecules recruit PcG complexes to the locus of transcription or to sites located elsewhere in the genome. An important role has been attributed to noncoding RNAs (ncRNAs) [63]. It has been postulated [28] that the increased chromatin condensation in the parous breast could have been initiated by ncRNAs, a postulate supported by the observed up regulation of several ncRNAs that included nuclear paraspeckle assembly transcript 1 (NEAT1), MALAT-1 (NEAT2) and X inactive specific transcript (XIST) [64] all critical components of the speckles. There is a relationship between the chromatin remodeling process and post transcriptional control maintained by the spliceosome machinery that is stored in nuclear speckles. Among the components of the spliceosome machinery that are up-regulated in the parous breast are the heterogeneous nuclear ribonucleoproteins HNRPA3, HNRPA2B1, HNRPD and HNRPU. The functional role of these HNRPs in the postmenopausal breast could be implicated in the regulation of mRNA stability, other functions like mammary gland involution, acting as negative regulators of telomere length maintenance [65] or regulating the trafficking of mRNA molecules [66]. Other members of the spliceosome complex are the small nuclear ribonucleoproteins (snRNPs), which function as suppressors of tumor cell growth and may have major implications as cancer therapeutic targets. Among these we have found that the transcripts regulated by the genes SF3B1, SFRS2, SFRS7, SFRS8, SFRS14, SFRS16, SNRP70, SNRPB, SNRPA1, PRF3 and PHF5A are over expressed in the parous breast [28]. Other members of the splicing factor compartment that are localized in the nuclear speckles are CCNL1 and CCNL2. It has been demonstrated that CCNL2 protein is overexpressed in the nucleus of epithelial cells composing the Lob 1 of the parous breast [28]. CCNL1 and CCNL2 are transcriptional regulators that participate in the pre-mRNA splicing process and the expression of critical factors leading to cell apoptosis, possibly through the Wnt signal transduction pathway $[67,68]$, which we found to be down regulated in the parous breast.

Another component of the spliceosome complex that regulates genes involved in the apoptotic process is the RNA binding motif protein 5 (RBM5). The over expression of RBM5 retards ascites associated tumor growth and enhances p53-mediated inhibition of cell growth and colony formation $[69,70]$ mechanisms that could also be operational in the parous breast. The spliceosome plays a critical role in differentiating mouse ESC and self-renewal, pluripotency and tissue lineage specification of human ESC [71]. Post-transcriptional modifications of RNA, including packaging into the nuclear speckles of the breast epithelial cells and recognition by RNA-binding proteins and/or microRNAs are crucial processes in differentiating breast epithelial cells. Although it is known that these regulatory mechanisms decrease the susceptibility of the cell to carcinogenesis, more studies need to be conducted for identifying the specific pathways involved in this process. Data discussed here emphasize the importance of posttranscriptional regulatory mechanisms as a critical component underlying the differentiation of the breast.

\section{Basis of the dual effect of late pregnancy in the premenopausal woman}

Recently, differences in gene expression in the breast of parous versus nulliparous healthy premenopausal women has been shown [72] by Santucci-Pereira and colleagues. The authors used Affymetrix Human Genome U133 Plus 2.0 microarrays, and analyzed the gene expression profile of breast tissue from 30 nulliparous (NP) and 79 parous $(\mathrm{P})$ premenopausal volunteers between the ages of 30 and 47 years who were free of breast pathology. Because of the known shortterm increase in breast cancer risk preceding the long-term protective effect of FTP, the authors also examined gene expression differences in $\mathrm{P}$ vs. NP women as a function of time since last FTP. Through multiple regression analysis, controlling for confounders, we found 416 probesets differentially expressed (fold-change $\geq 1.2$ and false discovery rate $<10 \%$ ) comparing all $\mathrm{P}$ vs. all $\mathrm{NP}$, and/or, $\mathrm{P}$ women whose last FTP was less than 5 years before biopsy vs. all NP women. Among these, 352 probesets, representing 238 genes, were up regulated, while 64 probesets, representing 48 genes, were down regulated in the parous compared to nulliparous breast. Of interest is that among the up regulated genes, they observed three expression patterns: 1) transient: genes up regulated after FTP but whose expression levels rapidly returned to nulliparous levels. These genes were mainly related to immune response (CCL5, CD48, IL7R); 2) long-term changing: genes up regulated following FTP, whose 
expression levels decreased with increasing time since last FTP, but did not return to nulliparous levels. These genes included genes related to immune response (CD38, CXCL10) and development (DKK3, LAMA2); and 3) long-term constant: genes that remained up regulated in the parous compared to nulliparous breast, independent of time since last FTP. These genes were mainly involved in developmental processes (BHLHE22, FZD8, KRT5), cell differentiation (RASGRP1, DSC3) and chromatin remodeling (NAP1L2). The Santucci-Pereira study shows that a first full term pregnancy induces long-term expression changes in genes related to the processes of development, cell differentiation and chromatin remodeling as has also be found in the parous postmenopausal breast [28]. Additionally, the transiently activated genes related to immune response during the first five years after FTP may play a role in the short-term increase of breast cancer risk following FTP. A better understanding of the molecular effects of parity on the breast may help the development of novel strategies for preventing breast cancer [72].

\section{Conclusions}

The genomic profile of nulliparous and parous women in the premenopausal and postmenopausal period has shown that there are genes which are only activated during the first five years after pregnancy that may contribute to the increased risk experienced by certain women after pregnancy $[28,47,48,72]$. At the same time pregnancy induces a long lasting genomic signature that starts after pregnancy, explaining its preventive effect. The molecular mechanism related to prevention revolves around the chromatin remodeling process [28].

\section{Funding}

NIH grant CA06927 to Fox Chase Cancer Center and an appropriation from the Commonwealth of Pennsylvania.

\section{Acknowledgment}

This work was supported by grant CA06927 to Fox Chase Cancer Center and by an appropriation from the Commonwealth of Pennsylvania.

\section{References}

1. Botha JL, Bray F, Sankila R, Parkin DM (2003) Breast cancer incidence and mortality trends in 16 European countries. Eur J Cancer 39: 1718-1729.

2. Clarke CA, Purdie DM, Glaser SL (2006) Population attributable risk of breast cancer in white women associated with immediately modifiable risk factors. BMC Cancer 6: 170.

3. Jemal A, Bray F, Center MM, Ferlay J, Ward E, et al. (2011) Global cancer statistics. CA Cancer J Clin 61: 69-90.

4. Althuis MD, Dozier JM, Anderson WF, Devesa SS, Brinton LA (2005) Global trends in breast cancer incidence and mortality 1973-1997. Int J Epidemiol 34: 405-412.

5. Maskarinec G, Pagano I, Chen Z, Nagata C, Gram IT (2007) Ethnic and geographic differences in mammographic density and their association with breast cancer incidence. Breast Cancer Res Treat 104: 47-56.

6. Nagata C, Mizoue T, Tanaka K, Tsuji I, Wakai K, et al. (2006) Tobacco smoking and breast cancer risk: an evaluation based on a systematic review of epidemiological evidence among the Japanese population. Jpn J Clin Oncol 36: 387-394.
7. Hinkula M, Pukkala E, Kyyrönen P, Kauppila A (2001) Grand multiparity and the risk of breast cancer: population-based study in Finland. Cancer Causes Control 12: 491-500.

8. MacMahon B, Cole P, Lin TM, Lowe CR, Mirra AP, et al. (1970) Age at first birth and breast cancer risk. Bull World Health Organ 43: 209-221.

9. Ma H, Henderson KD, Sullivan-Halley J, Duan L, Marshall SF, et al. (2010) Pregnancy-related factors and the risk of breast carcinoma in situ and invasive breast cancer among postmenopausal women in the California Teachers Study cohort. Breast Cancer Res 12: R35.

10. Phipps AI, Chlebowski RT, Prentice R, McTiernan A, Wactawski-Wende J, et al. (2011) Reproductive history and oral contraceptive use in relation to risk of triple-negative breast cancer. J Natl Cancer Inst 103: 470-477.

11. Toniolo P, Grankvist K, Wulff M, Chen T, Johansson R, et al. (2010) Human chorionic gonadotropin in pregnancy and maternal risk of breast cancer. Cancer Res 70: 6779-6786.

12. Mustacchi P (1961) Ramazzini and Rigoni-Stern on parity and breast cancer. Clinical impression and statistical corroboration. Arch Intern Med 108: 639-642.

13. Brinton LA, Sherman ME, Carreon JD, Anderson WF (2008) Recent trends in breast cancer among younger women in the United States. J Natl Cancer Inst 100: 1643-1648.

14. Kroman N, Melbye M, Mouridsen HT (2002) Prognostic influence of age at diagnosis in premenopausal breast cancer patients. Scand J Surg 91: 305-308.

15. Kroman N, Mouridsen HT (2003) Prognostic influence of pregnancy before, around, and after diagnosis of breast cancer. Breast 12: 516-521.

16. Downs JL, Wise PM (2009) The role of the brain in female reproductive aging. Mol Cell Endocrinol 299: 32-38.

17. Russo IH, Medado J, Russo J (1989) Endocrine Influences on Mammary Gland Structure and Development. Integument and Mammary Gland of Laboratory Animals (Jones, TC, Mohr, U, and Hunt, RD, Eds) Springer Verlag, Berlin, pp. 252-266.

18. Chen T, Lundin E, Grankvist K, Zeleniuch-Jacquotte A, Wulff M, et al. (2010) Maternal hormones during early pregnancy: a cross-sectional study. Cancer Causes Control 21: 719-727.

19. Albrektsen G, Heuch I, Thoresen S, Kvåle G (2006) Clinical stage of breast cancer by parity, age at birth, and time since birth: a progressive effect of pregnancy hormones? Cancer Epidemiol Biomarkers Prev 15: 65-69.

20. Beatson G (1896) On the treatment of inoperable cases of carcinoma of the mammary. Suggestions for new method of treatment with illustrative cases. Lancet 2: 104-107.

21. Lukanova A, Surcel HM, Lundin E, Kaasila M, Lakso HA, et al. (2012) Circulating estrogens and progesterone during primiparous pregnancies and risk of maternal breast cancer. Int J Cancer 130: 910-920.

22. Russo J, Russo IH, (eds) (2004) Molecular basis of breast cancer: Prevention and treatment. Springer-Verlag, Berlin, 447.

23. Russo J, Russo IH (2006) The role of estrogen in the initiation of breast cancer. J Steroid Biochem Mol Biol 102: 89-96.

24. Russo J, Russo IH (1980) Susceptibility of the mammary gland to carcinogenesis. II. Pregnancy interruption as a risk factor in tumor incidence. Am J Pathol 100: 497-512.

25. Medina D, Smith GH (1999) Chemical carcinogen-induced tumorigenesis in parous, involuted mouse mammary glands. J Natl Cancer Inst 91: 967-969.

26. Blakely CM, Stoddard AJ, Belka GK, Dugan KD, Notarfrancesco KL, et al. (2006) Hormone-induced protection against mammary tumorigenesis is conserved in multiple rat strains and identifies a core gene expression signature induced by pregnancy. Cancer Res 66: 6421-6431.

27. Russo J, Balogh GA, Heulings R, Mailo DA, Moral R, et al. (2006) Molecular basis of pregnancy-induced breast cancer protection. Eur $\mathrm{J}$ Cancer Prev 15: 306-342.

28. Russo J, Santucci-Pereira J, de Cicco RL, Sheriff F, Russo PA, et al. (2012) Pregnancy-induced chromatin remodeling in the breast of postmenopausal women. Int J Cancer 131: 1059-1070. 
29. Wagner KU, Boulanger CA, Henry MD, Sgagias M, Hennighausen L, et al. (2002) An adjunct mammary epithelial cell population in parous females: its role in functional adaptation and tissue renewal. Development 129: 1377-1386.

30. Booth BW, Boulanger CA, Smith GH (2008) Selective segregation of DNA strands persists in long-label-retaining mammary cells during pregnancy. Breast Cancer Res 10: R90.

31. Boulanger CA, Wagner KU, Smith GH (2005) Parity-induced mouse mammary epithelial cells are pluripotent, self-renewing and sensitive to TGF-betal expression. Oncogene 24: 552-560.

32. Russo J, Tay LK, Ciocca DR, Russo IH (1983) Molecular and cellular basis of the mammary gland susceptibility to carcinogenesis. Environ Health Perspect 49: 185-199.

33. Blackshaw S, Scholpp S, Placzek M, Ingraham H, Simerly R, et al. (2010) Molecular pathways controlling development of thalamus and hypothalamus: from neural specification to circuit formation. J Neurosci 30: $14925-14930$.

34. Hendriks AE, Laven JS, Valkenburg O, Fong SL, Fauser BC, et al. (2011) Fertility and ovarian function in high-dose estrogen-treated tall women. J Clin Endocrinol Metab 96: 1098-1105.

35. Russo J, Russo IH (1987) Development of the human mammary gland. In: Neville MC, Daniel C (eds) The Mammary Gland. Plenum, New York, pp 67-93.

36. Russo J, Rivera R, Russo IH (1992) Influence of age and parity on the development of the human breast. Breast Cancer Res Treat 23: 211-218.

37. Howell A, Evans GD (2011) Hormone replacement therapy and breast cancer. Recent Results Cancer Res 188: 115-124.

38. Lathi RB (2006) Implantation and placental physiology in early human pregnancy: the role of the maternal decidua and the trophoblast. In: De Groot L, Jameson LJ (eds) Endocrinology. Elsevier Saunders, Philadelphia, pp 3341-3351.

39. Parry S, Strauss F (2006) Placental hormones. In: De Groot L, Jameson L (eds) Endocrinology. Elsevier Saunders, Philadelphia, pp 3353-3367.

40. Alvarado M, Ho T-Y, Russo J, Russo I (1994) Human chorionic gonadotropin regulates the synthesis of inhibin in the ovary and the mammary gland of rats. Endocrine 2: 1107-1114.

41. Alvarado MV, Alvarado NE, Russo J, Russo IH (1994) Human chorionic gonadotropin inhibits proliferation and induces expression of inhibin in human breast epithelial cells in vitro. In Vitro Cell Dev Biol Anim 30A: 4-8.

42. Horikoshi Y, Matsumoto H, Takatsu Y, Ohtaki T, Kitada C, et al. (2003) Dramatic elevation of plasma metastin concentrations in human pregnancy: metastin as a novel placenta-derived hormone in humans. J Clin Endocrinol Metab 88: 914-919.

43. Russo IH, Koszalka M, Russo J (1991) Comparative study of the influence of pregnancy and hormonal treatment on mammary carcinogenesis. Br J Cancer 64: 481-484.

44. Russo J, Russo IH (1997) Role of differentiation in the pathogenesis and prevention of breast cancer. Endocr Relat Cancer 4: 7-21.

45. Russo J, Balogh GA, Russo IH (2008) Full-term pregnancy induces a specific genomic signature in the human breast. Cancer Epidemiol Biomarkers Prev 17: 51-66.

46. Russo IH, Russo J (2011) Pregnancy-induced changes in breast cancer risk. J Mammary Gland Biol Neoplasia 16: 221-233.

47. Belitskaya-Lévy I, Zeleniuch-Jacquotte A, Russo J, Russo IH, Bordás P, et al. (2011) Characterization of a genomic signature of pregnancy identified in the breast. Cancer Prev Res (Phila) 4: 1457-1464.

48. Peri S, de Cicco RL, Santucci-Pereira J, Slifker M, Ross EA, et al. (2012) Defining the genomic signature of the parous breast. BMC Med Genomics 5: 46 .

49. Golob JL, Paige SL, Muskheli V, Pabon L, Murry CE (2008) Chromatin remodeling during mouse and human embryonic stem cell differentiation. Dev Dyn 237: 1389-1398.
50. Asztalos S, Gann PH, Hayes MK, Nonn L, Beam CA, et al. (2010) Gene expression patterns in the human breast after pregnancy. Cancer Prev Res (Phila) 3: 301-311.

51. Wilson BJ, Giguère V (2008) Meta-analysis of human cancer microarrays reveals GATA3 is integral to the estrogen receptor alpha pathway. Mol Cancer 7: 49.

52. Chou J, Provot S, Werb Z (2010) GATA3 in development and cancer differentiation: cells GATA have it! J Cell Physiol 222: 42-49.

53. D'Cruz CM, Moody SE, Master SR, Hartman JL, Keiper EA, et al. (2002) Persistent parity-induced changes in growth factors, TGF-beta3, and differentiation in the rodent mammary gland. Mol Endocrinol 16: 2034-2051.

54. Medina D (2004) Breast cancer: the protective effect of pregnancy. Clin Cancer Res 10: 380S-384S.

55. Russo IH, Russo J (1996) Mammary gland neoplasia in long-term rodent studies. Environ Health Perspect 104: 938-967.

56. Russo J, Tait L, Russo IH (1983) Susceptibility of the mammary gland to carcinogenesis. III. The cell of origin of rat mammary carcinoma. Am J Pathol 113: 50-66.

57. Bussolati G, Marchiò C, Gaetano L, Lupo R, Sapino A (2008) Pleomorphism of the nuclear envelope in breast cancer: a new approach to an old problem. J Cell Mol Med 12: 209-218.

58. Palmer JE, Sant Cassia LJ, Irwin CJ, Morris AG, Rollason TP (2008) The prognostic value of nuclear morphometric analysis in serous ovarian carcinoma. Int J Gynecol Cancer 18: 692-701.

59. Tan PH, Goh BB, Chiang G, Bay BH (2001) Correlation of nuclear morphometry with pathologic parameters in ductal carcinoma in situ of the breast. Mod Pathol 14: 937-941.

60. Cao R, Wang L, Wang H, Xia L, Erdjument-Bromage H, et al. (2002) Role of histone H3 lysine 27 methylation in Polycomb-group silencing. Science 298: 1039-1043.

61. Kubicek S, Schotta G, Lachner M, Sengupta R, Kohlmaier A, et al. (2006) The role of histone modifications in epigenetic transitions during normal and perturbed development. Ernst Schering Res Found Workshop : 1-27.

62. Lin W, Dent SY (2006) Functions of histone-modifying enzymes in development. Curr Opin Genet Dev 16: 137-142.

63. Guenther MG, Young RA (2010) Transcription. Repressive transcription. Science 329: 150-151.

64. Erwin JA, Lee JT (2010) Characterization of X-chromosome inactivation status in human pluripotent stem cells. Curr Protoc Stem Cell Biol Chapter 1: Unit 1B.

65. Huang PR, Hung SC, Wang TC (2010) Telomeric DNA-binding activities of heterogeneous nuclear ribonucleoprotein $\mathrm{A} 3$ in vitro and in vivo. Biochim Biophys Acta 1803: 1164-1174.

66. Han SP, Friend LR, Carson JH, Korza G, Barbarese E, et al. (2010) Differential subcellular distributions and trafficking functions of hnRNP A2/B1 spliceoforms. Traffic 11: 886-898.

67. Loyer P, Trembley JH, Grenet JA, Busson A, Corlu A, et al. (2008) Characterization of cyclin L1 and L2 interactions with CDK11 and splicing factors: influence of cyclin L isoforms on splice site selection. J Biol Chem 283: 7721-7732.

68. Yang L, Li N, Wang C, Yu Y, Yuan L, et al. (2004) Cyclin L2, a novel RNA polymerase II-associated cyclin, is involved in pre-mRNA splicing and induces apoptosis of human hepatocellular carcinoma cells. J Biol Chem 279: 11639-11648.

69. Fushimi K, Ray P, Kar A, Wang L, Sutherland LC, et al. (2008) Upregulation of the proapoptotic caspase 2 splicing isoform by a candidate tumor suppressor, RBM5. Proc Natl Acad Sci U S A 105: 15708-15713.

70. Kobayashi T, Ishida J, Musashi M, Ota S, Yoshida T, et al. (2011) p53 transactivation is involved in the antiproliferative activity of the putative tumor suppressor RBM5. Int J Cancer 128: 304-318.

71. Salomonis N, Schlieve CR, Pereira L, Wahlquist C, Colas A, et al. (2010) Alternative splicing regulates mouse embryonic stem cell pluripotency and differentiation. Proc Natl Acad Sci U S A 107: 10514-10519. 
Citation: Russo J (2014) Prevention of Breast Cancer Could Be a Consequence of Pregnancy: A Review. J Gen Pract 2: 167. doi: $10.4172 / 2329-9126.1000167$

Page 7 of 7

72. Santucci-Pereira J, Zeleniuch-Jacquotte A, Afanasyeva Y, Zhong H, Peri $S$, et al. (2014) Gene expression profile induced by pregnancy in the breast of premenopausal women. Proc Am Assoc Cancer Res Annual Mtg: 2360A 